\title{
Research on Green Total Factor Productivity Estimation and Decomposition of China's Transportation Industry
}

\author{
Ruizhe Wang \\ School of Economics and Management, Beijing Jiaotong University, Beijing 100044, China. \\ ruizwang@bjtu.edu.cn
}

Keywords: Transportation, Green total factor productivity, Zofio decomposition.

\begin{abstract}
China's transportation development has entered a new era, and TFP estimation needs to be combined with the new development concept. This paper uses China's provincial panel data and Malmquist-luenberger (ML) index method to measure the green total factor productivity of the transportation industry in China, and it also analyzes the whole change trend and regional characteristics about the total factor productivity of the transportation industry combining the Zofio decomposition method. The results show that: The traditional method of Malmquist index that ignores the unexpected output will underestimate total factor productivity and technical change, and will overestimate the technical efficiency. The green total factor productivity of the transportation industry in China shows a downward trend under the condition of reducing energy and emission because of the decline of pure technical efficiency before 2007 and the decline of pure technical efficiency change after 2008 .
\end{abstract}

\section{Introduction}

China's transportation industry has changed rapidly since 1978. By the end of 2017, China has built 25 thousand kilometers of HSR, 136.5 thousand kilometers of expressway, and the integrated transportation infrastructure network of railway, highway and water carriage is almost completed. However, the large transportation infrastructure scale and complex network system have also brought many challenges to the transportation industry in the transition period of China. The marginal benefit of the traffic investment is reducing; the profit of the transport enterprises is declining. Moreover, problems caused by the negative externality of traffic congestion and pollution are becoming increasingly prominent.

With the increasingly adverse impact on the environment, the calculation of the production efficiency of China's transportation industry must take into account the "bad output" of environmental pollution. Chung et al. introduces the Malmquist-luenberger(ML) exponents of the directional distance function, provides an effective method for the related research[1].Abrate\&Erbetta, Krautzberger\&Wetze used the ML index to measure the total factor productivity (TFP) of the Italy Airport Inc. and European commercial transport industry under the constraints of carbon emissions[2,3]. Lee used this method to measure the TFP of major airlines, as well as made an empirical study on its influencing factors [4].

In summary, this paper will consider the energy and environmental constraints, and calculate the Malmquist-luenberger (ML) index of China's transportation industry. In addition, in order to analyze the growth mechanism of green TFP in China's transportation industry, this paper decomposes it from four aspects: institutional level, pure technological progress, scale return change and scale preference of technology change.

\section{Research Method and Data Collection}

Method. In recent years, the most widely used methods of measuring TFP are stochastic frontier analysis (SFA) and data envelopment analysis (DEA). SFA is a parameter method; it needs to set up a specific production function, construct the boundary of the parameter production, and measure the change of TFP by the sum of the efficiency change and the technological change. Unlike the SFA method, the DEA method is a non-parametric method. It does not need to know the specific form of 
the production function, and estimates the TFP change index by calculating the distance function. It has the advantages of less constraint. As a result, this paper uses the DEA method to measure the ML index of China's inter provincial transportation industry.

The ML index proposed by Chung et al. is used to measure the TFP of transportation industry under the constraints of energy-saving and emission-reducing, the ML index of $t+1$ period based on the $\mathrm{t}$ period is as Equation (1):

$$
M L_{t}^{t+1}=\sqrt{\frac{1+D_{0}^{t}\left(x^{t}, y^{t}, u^{t} ; y^{t},-u^{t}\right)}{1+D_{0}^{t}\left(x^{t+1}, y^{t+1}, u^{t+1} ; y^{t+1},-u^{t+1}\right)} \mathrm{g} \underset{1+D_{0}^{t+1}\left(x^{t+1}, y^{t+1}, u^{t+1} ; y^{t+1},-u^{t+1}\right)}{r}\left(x^{t}, y^{t}, u^{t} ; y^{t},-u^{t}\right)}
$$

Fare et al. using the CRS-DEA model (Equation (2)) to decompose the ML index into the technical change index (TC) and the technical-efficiency change index (EC) [5].

$$
\begin{aligned}
& M L_{\mathrm{t}}^{t+1}=T C \times E C
\end{aligned}
$$

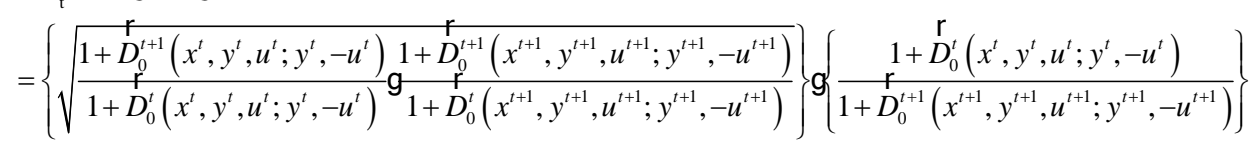

In Equation (2), $M L_{t}^{t+1}$ measure is the change of productivity from $\mathrm{t}$ to $\mathrm{t}+1$ period. If $\mathrm{ML}>1$, the overall production efficiency is improved; if $\mathrm{ML}=1$, it is constant; and if $\mathrm{ML}<1$, it is decreased. TC indicates the technical progress, if TC $>1$, the possibility boundary of production from $t$ to $t+1$ period, is moving in the direction of increasing expected output and reducing undesired output. EC indicates the technical efficiency, if $\mathrm{EC}>1$, the $\mathrm{t}+1$ period is closer to the production boundary than $\mathrm{t}$, and the efficiency is progressive.

Followed these studies, this paper adopts the Zofio decomposition method to consider the TFP under the condition of constant scale return and variable scale return, and then introduced scale effect to decompose TC into pure technical change index (PTC) and scale technical change index (STC), and EC into pure technical efficiency change index (PEC) and scale efficiency change index (SEC) [6]. The ML index is shown as Equation (3):

$$
M L_{\mathrm{t}}^{t+1}=T C \times E C=P T C \times S T C \times P E C \times S E C
$$

In Equation (3), ML is the TFP under constraint of constant scale return. PTC indicates the pure technical change, if PTC $>1$, the technology is progressed; if PTC $<=1$, it is unchanging or retreating. STC reflects whether the technology achieved to the optimal scale, if STC $>/=/<1$, the technological change deviates from/equal to /ahead of the optimal scale. PEC indicates the pure technical efficiency under variable scale return, measures changes in management and system level. If PEC $\rangle|=|<1$, the level of management and system has been improved/unchanged/declined, and promoted/stabilized/ suppressed the production efficiency. SEC shows a change in scale return, if SEC $>/=\mid<1$, the DMU achieved economies of scale/constant scale/diseconomies of scale.

Indicators Selection and Data Collection. All of the original data come from EPS database, China Statistical Yearbook and China Energy Statistics Yearbook. The sample dataset collected by provinces from 2000 to 2016. And considering too much missing values of Tibet, as its the propotion is very low, so the relevant data of Tibet are not included in this paper.

Expected output: According to the conversion method of passenger and cargo stipulated by China National Bureau of Statictics, the expected ouput variable is measured by a mixed turnover of conversion of freight turnover and passenger turnover. Due to the limitation of data accessibility, this paper does not include the air turnover, and the turnover of passenger and cargo transportation in railway and waterways is directly added, while the turnover of highway goods should be multiplied by the conversion factor of 0.1 .

Unexpected output: exhaust emission is the main way of environmental pollution in transportation industry. Therefore, the the unexpected ouput variable is measured by carbon emissions of six main sources of energy, including coal, gasoline, kerosene, diesel oil, fuel oil and natural gas. In the conversion of carbon emissions, this paper adopts Zhao et al.'s method[7], and according to the IPCC Guide, the carbon emissions are calculated by equition (4): 


$$
A=\sum_{i=1}^{6}\left(B_{i} \times C_{i}\right)
$$

A indicates the amount of carbon emissions, B indicates the energy consumption converted to standard coal, and $\mathrm{C}$ indicates the carbon emission coefficient of various energy sources. When converting to standard coal, the average low calorific value of each energy is taken from the China Statistical Yearbook, and the reference coefficient used for conversion is shown in Table 1.

Table 1 Reference Coefficient Used for Carbon Emission Conversion

\begin{tabular}{cccc}
\hline Energy & $\begin{array}{c}\text { Average Low } \\
\text { Calorific Value }\end{array}$ & $\begin{array}{c}\text { IPCC }(2006) \text { Carbon } \\
\text { Emission Coefficient }\end{array}$ & $\begin{array}{c}\text { Standard Coal } \\
\text { Convertion Coefficient }\end{array}$ \\
\hline Coal & $20908 \mathrm{kj} / \mathrm{kg}$ & $25.8 \mathrm{kgc} / \mathrm{gj}$ & $0.7143 \mathrm{~kg} \mathrm{SC} / \mathrm{kg}$ \\
Gasoline & $43070 \mathrm{kj} / \mathrm{kg}$ & $18.9 \mathrm{kgc} / \mathrm{gj}$ & $1.4714 \mathrm{~kg} \mathrm{SC} / \mathrm{kg}$ \\
Kerosene & $43070 \mathrm{kj} / \mathrm{kg}$ & $19.5 \mathrm{kgc} / \mathrm{gj}$ & $1.4714 \mathrm{~kg} \mathrm{SC} / \mathrm{kg}$ \\
Diesel Oil & $42652 \mathrm{kj} / \mathrm{kg}$ & $20.2 \mathrm{kgc} / \mathrm{gj}$ & $1.4571 \mathrm{~kg} \mathrm{SC} / \mathrm{kg}$ \\
Fuel Oil & $41816 \mathrm{kj} / \mathrm{kg}$ & $21.1 \mathrm{kgc} / \mathrm{gj}$ & $1.4286 \mathrm{~kg} \mathrm{SC} / \mathrm{kg}$ \\
Natural Gas & $38931 \mathrm{kj} / \mathrm{m} 3$ & $15.3 \mathrm{kgc} / \mathrm{gj}$ & $1.3300 \mathrm{~kg} \mathrm{SC} / \mathrm{m} 3$ \\
\hline
\end{tabular}

Capital Input: As the relative efficiency measured by the DEA-ML index, the result will not have a significant deviation as long as the research objects remain relative consistency[8]. Deng[9], Yu\&Liu[10], adopted the fixed assets investment as capital input indicator, thus this paper follows this method and collects the investment amount of fixed assets of transportation industry as capital input.

Labor Input: This paper uses the number of employees in transportation industry as labor input indicator. For no direct data indicated the transportation employees, so this paper calculates it by total number of employees of transportation, storage, post and telecommunications industry minus number of employees of storage, post and telecommunications industry.

Energy Input: Transportation industry is a typical energy consuming industry, and one of the fastest growing industries of energy consumption. In this paper, the energy input is measured by primary energy consumption, the selection of energy types is consistent with the unexpected output, and the total energy input of each region is obtained by converting into standard coal.

The descriptive statistical analysis of input and output variables is shown in Table 2.

Table 2 Descriptive Statistical Results

\begin{tabular}{ccccccc}
\hline & & Unit & Mean & Std.Dev. & Min & Max \\
\hline \multirow{3}{*}{ Input Variables } & Capital Input & 100 million yuan & 444.80 & 466.64 & 9.79 & 2934.76 \\
& Labor Input & 10 thousand people & 18.56 & 10.51 & 1.20 & 67.26 \\
& Energy Input & 10 thousand ton SC & 557.04 & 505.82 & 0.82 & 2872.79 \\
Expected Output & Mixed Turnover & 100 million km & 2731.64 & 3158.47 & 63.37 & 20296.11 \\
Unexpected Output & Carban Emission & 10 thousand ton & 243.43 & 209.73 & 0.87 & 1175.32 \\
\hline
\end{tabular}

\section{Empirical results and analysis}

The Change Characteristics of Green TFP in China's Transportation Industry. In order to reflect the impact of energy saving and emission reduction restrictions on the TFP of the transportation industry, this paper uses MaxDEA PRO software to measure the TFP of each DMU in two cases: The first case is the traditional Malmquist Productivity Index (M) that does not consider undesired outputs. The second case is the Malmquist-luenberger index (ML) that considers energy conservation and emission reduction targets. The empirical results are shown in Table 3.

From the empirical results in Table 3, the average annual change in green TFP of China's transportation industry in 2000-2016 is generally declining, and the ML_TFP index is deceased by $2 \%$.The main factor causing the decline in green TFP is Technical efficiency $(-2.5 \%)$, while the technology advancement index increased by $0.6 \%$. From the specific changes in each year, although the ML_TFP index has not changed significantly, the technical efficiency has increased substantially. The annual growth rate of the ML_EC index from 2000 to 2007 was $-18.4 \%$, but from 2008 to 2016, the average annual growth rate has become $15.8 \%$.Contrary to the technical efficiency index, the technological progress index shows a significant downward trend, but the time division of the change 
phase is basically consistent with the technical efficiency. From 2000 to 2007, the ML_TC index increased by an average of 20.5 percentage points per year, while from 2007 to 2016, the same index fell by $15.1 \%$ annually. According to the above analysis, the technological progress from 2000 to 2007 is the main driving force for the green TFP of China's transportation industry, and the effect of technical efficiency improvement from 2008 to 2016 is more significant. Comparing the TFP in the two cases, under the constraints of energy conservation and emission reduction, the TFP and technological progress index of China's transportation industry have been improved, while the technical efficiency index has declined.

Table 3 Comparison of TFP MI Index and ML Index of Transportation Industry in Major Years

\begin{tabular}{ccccccc}
\hline Year & M_TFP & ML_TFP & M_EC & ML_EC & M_TC & ML_TC \\
\hline 2000 & 0.906 & 0.871 & 0.461 & 0.446 & 1.963 & 1.954 \\
2007 & 0.927 & 0.946 & 0.882 & 0.948 & 1.052 & 0.997 \\
2012 & 1.013 & 1.044 & 1.039 & 1.150 & 0.975 & 0.908 \\
2014 & 1.011 & 0.991 & 1.446 & 1.433 & 0.699 & 0.692 \\
2015 & 0.780 & 0.773 & 1.228 & 1.283 & 0.635 & 0.602 \\
2016 & 1.041 & 1.051 & 0.966 & 0.822 & 1.078 & 1.278 \\
$2000-2016$ & 0.963 & 0.980 & 0.980 & 0.975 & 0.982 & 1.006 \\
\hline
\end{tabular}

General Characteristics of Green TFP of Transportation Industry in China's Provinces. In order to reflect the regional differences in the green TFP of China's transportation industry, this paper analyzes the differences in the changes in green TFP of the transportation industry in each province. In the analysis, the TFP measurement is performed for each DMU in two cases. The empirical results are shown in Table 4, here lists the calculation results of major provinces and cities.

Table 4 Comparison of TFP MI Index and ML Index of Transportation Industry

\begin{tabular}{ccccccccc}
\hline \multirow{2}{*}{ Sequence } & \multicolumn{3}{c}{ Case1 } & \multicolumn{5}{c}{ Case2 } \\
\cline { 2 - 8 } & DMU & M_EC & M_TC & M_TFP & DMU & ML_EC & ML_TC & ML_TFP \\
\hline 1 & Zhejiang & 1.038 & 1.044 & 1.083 & Shanghai & 1.000 & 1.058 & 1.058 \\
2 & Fujian & 1.017 & 1.026 & 1.044 & Zhejiang & 1.041 & 1.009 & 1.050 \\
3 & Shanghai & 1.000 & 1.033 & 1.033 & Fujian & 1.021 & 1.005 & 1.026 \\
28 & Shandong & 0.950 & 0.950 & 0.902 & Heilongjiang & 0.923 & 1.012 & 0.935 \\
29 & Heilongjiang & 0.930 & 0.967 & 0.900 & Sichuan & 0.940 & 0.995 & 0.935 \\
30 & Jilin & 0.909 & 0.961 & 0.873 & Jilin & 0.919 & 1.001 & 0.921 \\
\hline
\end{tabular}

As shown in the empirical results in Table 4: Those provinces with green TFP in the transportation industry greater than 1 include Shanghai(5.8\%), Zhejiang(5.0\%), Fujian(2.6\%) and other five province, accounting for $26.67 \%$ of the total research area. Jilin(--7.9\%), Sichuan(-6.5\%), and Heilongjiang(-6.5\%) are the provinces with the largest decline in ML_TFP. Compared with the traditional M_TFP, the green TFP of the transportation industry in 23 provinces has increased, accounting for $76.67 \%$ of the total research area. Hubei, Jilin and Hebei are the provinces with the largest increase, while Zhejiang, Hainan and Fujian are the provinces with the largest decline. In terms of ML_EC, the value of most regions has decreased compared with the traditional M_EC, and only Inner Mongolia, Jilin and Gansu have increased by about $1 \%$. However, the composition and quantity of provinces with technical efficiencies greater than 1 have not changed. The declines in Jilin(-8.1\%), Heilongjiang(-7.7\%) and Sichuan(-6.0\%) are still the largest. In terms of TC, after considering energy conservation and emission reduction constraints, the areas with the greatest technological advancement were Shanghai (5.8\%), Hebei (2.1\%) and Jiangxi (1.3\%). The TC decline in Hainan is the most obvious, at $-2.7 \%$, while the decline in other areas is mostly around $-0.5 \%$. Unlike EC, ML_TC in 26 provinces has increased compared to M_TC. Sichuan, Jiangsu and Liaoning have the largest increases, while Zhejiang, Fujian and Hainan have the largest declines.

Compared with M_TFP, the ML_TFP of all provinces in China has generally improved. This result shows that during the research period, the development of China's transportation industry has implemented the goal of energy conservation and emission reduction, and achieved some positive results. After considering the undesired output, the TC in the provinces have generally improved significantly, but the EC has declined. This result shows that the current low technical efficiency is 
an important reason for restricting the improvement of the green TFP of China's transportation industry.

Decomposition of Green TFP in China's Transportation Industry.In order to analyze the trend and characteristics of green TFP in China's transportation industry, this paper uses Zofio's decomposition method to classify green TFP of China's transportation industry into scale efficiency change (SEC), scale technology change (STC), pure technology change (PTC) and pure technical efficiency change (PEC), the calculation results are shown in Figure 1.

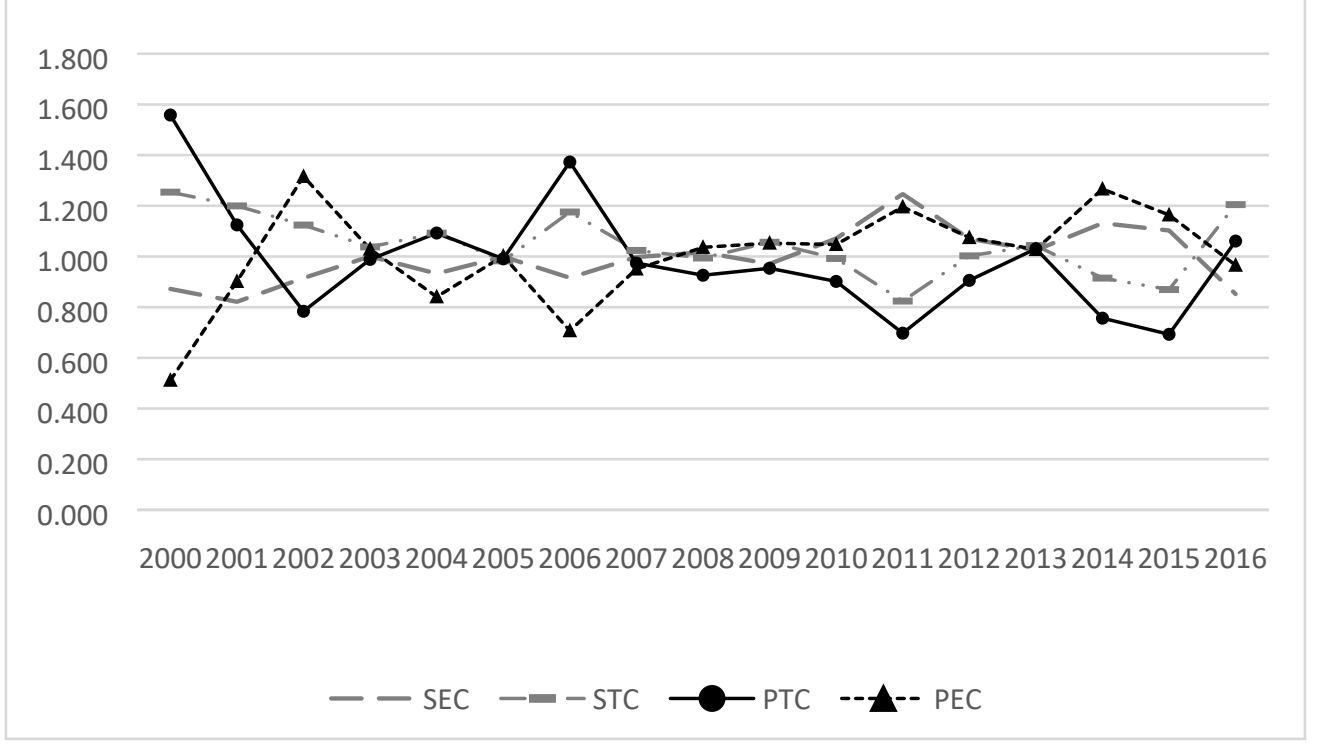

Fig. 1 Zofio Decomposition of Green TFP in China's Transportation Industry

According to the results of Zofio decomposition, the effect of scale on the change of green TFP in China's transportation industry is significant. Between 2000 and 2016, China's transportation industry PTC and PEC fell by $3.3 \%$ and $2.6 \%$ per year. Compared with the $0.6 \%$ increase of TC and the $2.5 \%$ decline of EC before decomposition, the decline of PTC and PTC has expanded. After considering the scale effect, the SEC fell by $0.9 \%$, while the STC increased by 4 percentage points. The STC is the only one of the four indicators that is greater than 1 . This result shows that China's transportation industry needs to further improve its basic innovation capability and management efficiency. The technical level of China's transportation industry has lagged behind its construction scale and requires more R\&D investment.

From the perspective of time series, as shown in Figure 1, the difference among the four indicators shows a significant "U" shape. Similar to the pre-decomposition, the trend of each index during the study period can be divided into two stages: 2000-2007 and 2008-2016. From 2000 to 2007, the main driving force for the improvement of green TFP in China's transportation industry was technological progress, especially the scale technology change, which increased by $10.8 \%$. Among other indexes, pure technology changes increased by $8.8 \%$, while scale technical efficiency and pure technical efficiency decreased by $7.7 \%$ and $12.2 \%$.From 2008 to 2016, it showed completely different characteristics. The improvement of EC has become the main force to promote the growth of green TFP in the transportation industry. Among the four decomposition indexes, the pure technical efficiency has increased by $8.8 \%$, and the technical efficiency of scale has increased. $4.9 \%$. Compared with the previous stage, the promotion of technological progress has been significantly reduced, the scale technology change has decreased by $1.7 \%$, and the pure technology change has decreased by $12.9 \%$.

\section{Conclusion}

Based on the panel data of 30 provinces from 2000 to 2016 in China, this paper analyzes the change trend of green TFP in the transportation industry by using DEA-ML method and Zofio decomposition method. The empirical results show that: (1) the traditional Malmquist method, which ignores unexpected output, will underestimate the TFP and TC and overestimate the technical efficiency of 
transportation industry. However, it explains that China's transportation industry has gained some achievements in energy conservation and environmental protection technology innovation in recent years, while it also sacrificed some technical efficiency while pursuing the goal of energy saving and emission reducing. (2) Although the influence of scale effect was significant, the green TFP of transportation industry in China showed a downward trend, and the main reason for this trend was the reduction of technical efficiency. (3) The development of green TFP in China's transportation industry can be divided into before and after 2007. The decrease of technical efficiency before 2007, especially the decline of PEC, is the main cause of the decrease of TFP. The decline of PTC from 2008 has become the main reason for reducing TFP, and EC's improvement played a supporting role.

\section{References}

[1] Chung Y H, Färe R, Grosskopf S. Productivity and undesirable outputs: a directional distance function approach[J]. Journal of environmental management, 1997, 51(3): 229-240.

[2] Abrate G, Erbetta F. Efficiency and patterns of service mix in airport companies: An input distance function approach $[\mathrm{J}]$. Transportation research part e: logistics and transportation review, 2010, 46(5): 693-708.

[3] Krautzberger L, Wetzel H. Transport and $\mathrm{CO}_{2}$ : productivity growth and carbon dioxide emissions in the european commercial transport industry[J]. Environmental and resource economics, 2012, 53(3): 435-454.

[4] Lee B L, Wilson C, Pasurka C A, et al. Sources of airline productivity from carbon emissions: an analysis of operational performance under good and bad outputs[J]. Journal of productivity analysis, 2016: 1-24.

[5] Färe R, Grosskopf S, Norris M, et al. Productivity growth, technical progress, and efficiency change in industrialized countries[J]. American economic review, 1994: 66-83.

[6] Zofio J L. Malmquist productivity index decompositions: a unifying framework[J]. Applied economics, 2007, 39(18): 2371-2387.

[7] Zhao M, Zhang W,Yu L. Carbon emissions from energy consumption in Shanghai city[J]. Research of Environmental Sciences, 2009, (08): 984-989.

[8] Liu B, Li Q.The dynamic analysis of China's city TFP:1990-2006--based on the malmquist index and DEA model[J]. Nankai economic studies, 2009, (03): 139-152.

[9] Deng X, Wang X, Ng A S F, Lin Y. Analysis of the total factor productivity of Chinese Logistics Companies[J]. Systems engineering, 2008, (06): 1-9.

[10] Yu Y, Liu B. An empirical analysis on technological progress and its influencing factors in regional logistics industry[J]. Shanghai econmic review,2010, (10): 3-12. 